\title{
The Research Value of Visual Symbols in the Inheritance of Spring Festival Customs - Taking Foshan, Guangdong as an Example
}

\author{
Dapeng Zhou ${ }^{1, *}$ \\ ${ }^{1}$ School of Art and Design, Gungdong Industy Polytechnic, Guangzhou, Guangdong 510300, China \\ *Corresponding author. Email: zhoudapeng@126.com
}

\begin{abstract}
The Spring Festival is the most solemn festival for the Chinese. Its inheritance and continuity are of great value to Chinese culture. Foshan Spring Festival customs have formed unique local customs based on the integration of the Central Plains culture. Its Spring Festival customs are systematically elaborated from the research perspective of design, and its significance and value are affirmed. What's more, its visual symbols are comprehensively studied through the intervention of visual communication design to construct a scientific symbol recognition system, and grasp the general characteristics of Foshan's Spring Festival symbols. Besides, the deep connotation of its cultural symbols, such as ethical education, worship of ancestors, praying for good fortune, seeking benefits and avoiding disasters, compatibility and friendship, harmony and goodwill, has also been explored, laying the foundation for the subsequent exploration of the possible application of innovative cultiral creation, which is a pioneering exploration of the protection of intangible cultural heritage of Foshan Spring Festival customs through visual communication design.
\end{abstract}

Keywords: Intangible cultural heritage, Spring Festival, Visual communication design.

\section{INTRODUCTION}

The Spring Festival is the most attended and solemn festival for the Chinese people. It carries the moral and ethics of the Chinese nation, it is in line with the common pursuit of mankind, and it embodies the essence of the Chinese nation's cultural thoughts. Foshan's Spring Festival has formed a unique local custom based on the integration of the Central Plains culture. The main content is the food, clothing, housing, transportation and prayers for the gods in the Spring Festival, its prominent feature is the large-

*Project: This article is one of the results of the 2017 Guangzhou "Thirteenth Five-Year" Social Science Planning Project "Aesthetic Research on the Visual Symbols of Chinese Traditional Years in the Context of Contemporary Design" (201763); The outcome of the 2020 Foshan Social Science Planning Project "Research and Redesign of Visual Symbols in the Inheritance of Foshan Spring Festival Customs" (2020GJ044). The phase results of 2020 Guangdong Industry Polytechnic Humanities and Social Science Research Project Key Project "Research on Visual Symbols Redesign in Guangzhou Spring Festival Customs and Year Cultural Inheritance" (SK2020-002). scale group activities, and the participation of the whole people in harmony and joy is the core value of Spring Festival in Foshan. Entering the 21st century, in the context of the fierce economic globalization, the cultural localization, individualization and diversification presented by the trend spread globally. The transformation of lifestyle driven by technology is accompanied by the rapid iterative development of design concepts and design practices. The internationalist design style that has ruled for nearly a century that emphasizes functions and neglects humanities, regional characteristics and historical context has been more and more questioned. Regional, national, and historical design language expressions are changing from secondary and subordinate technical concepts to contemporary design aesthetics and consumer trends with dominant status. With the accelerating process of Chinese society's transformation from a traditional agricultural society to a modern industrial society, China is rapidly and efficiently integrating into the world. The Spring Festival as the most respected festival 
in Chinese society is now due to various reasons, so that many contents of the custom are gradually diminishing, and corresponding support and protection measures are urgently needed. Through the methods and means of visual communication design, inheriting and developing Spring Festival customs, creating a festive atmosphere, are important for building a harmonious society, improving the quality of urban culture and people's happiness, and promoting excellent traditional culture.

\section{OVERVIEW OF FOSHAN SPRING FESTIVAL CUSTOMS}

Foshan Spring Festival customs are the grandest, most solemn and longest festival customs in Foshan, lasting from December (the twelfth lunar month) of the lunar calendar to the 26th of January (first lunar month) of the second year. It reflects the folk culture and art of Foshan more systematically and intensively. It can be regarded as a model of folk customs that integrates Lingnan Cantonese culture. Its wide influence, many participants, and rich content have been passed down to the current days. Foshan's Spring Festival customs were included in the second batch of Guangdong's Intangible Cultural Heritage List in 2007.

Foshan Spring Festival customs can be roughly divided into three categories according to the form and time of expression:

- From the end of the twelfth lunar month to the 30th of the month, it is the twelfth lunar month to welcome the lunar New Year, including sacrificing the kitchen god, sweeping the house, swaying the spring, opening the oil pot, shopping on the flower street, selling laziness, lighting the lights on New Year's Eve, and blaming the year ("blaming" means "to press"), etc.

- From the first day of the first lunar month to the fifteenth day of the first lunar month, it is called as Xinzheng. New Year's customs include burning firecrackers, welcoming the God of Wealth, buying big clams, singing Hezheng dragon boat songs and carp songs, New Year greetings, walking silver roads, and Dancing Lions harvesting the tea to celebrating the new year.

- The custom of praying for blessings during the Spring Festival is rich in content, diverse in forms and distinctive in features, including visiting the ancestral temple on the first day of the new year, praying for blessings, Lantern Festival and Lunar Lanterns, Lantern Festival outing, lettuce fair, burning fireworks and performing the operas, walking through the Tongji Bridge on the 16th of the first lunar month and so on.

Especially walking through the Tongji Bridge on the 16th of the first lunar month is the most distinctive. It is the most familiar and widelyparticipated Spring Festival custom in Foshan. The proverb of "going through Tongji Bridge, there will be no disease" has been circulating in Foshan for hundreds of years. On the 16th day of the first month of the lunar calendar, local people in Foshan, men, women, and children in the four townships join in groups, bring men and women, walk to Tongji Bridge, or burn incense candles and firecrackers in the community, or step into Nanji Guanyin Temple to burn incense, pray to the gods and bow down to worship, the man asks for a lottery, while the woman pulls on the lantern belts in front of the god, asking for descendants and wealth. Then it is necessary to buy a "traveling windmill" and take the parade on the Tongji Bridge, and people must travel from the bridge head (north bank) to the end of the bridge at one time, and they cannot turn back and forth. Since its development and evolution, going through the Tongji Bridge has become the largest folk cultural activity in Foshan.

\section{RESEARCH SIGNIFICANCE AND VALUE}

Foshan Spring Festival does have its unique and distinctive local characteristics. The author summarizes and organizes the theoretical cognition from Foshan's local cultural visual symbols, and provides typical methods, paradigms, types and stylized reference samples in actual design behaviors.

Based on the contemporary, paying attention to daily life, the researchers can interpret, sort and summarize the traditional Chinese New Year visual cultural symbols through the visual communication design, contemporary design application environment and visual aesthetic perspectives. Through design practice, the theoretical research results can be applied to the development and design of cultural creative products, and through redesign methods, traditional culture can be inherited and carried forward from the perspective of design practice and aesthetics. Foshan traditional year culture is a highly concentrated cultural heritage representative of the festival culture in the 
Lingnan region. It is a highly concentrated cultural heritage of the Cantonese festival in the Lingnan culture. In-depth exploration and summary of their visual symbol characteristics, style and spirit, through systematic combing and constructing a modern design symbol system, have practical significance for stimulating the Spring Festival holiday economy and guiding the production and design behavior of cultural and creative industries. Through the study of these issues, it is possible to dig out the roots of Lingnan's traditional life aesthetic thoughts, in order to enrich the construction of the cultural and creative industry, build and improve the soft power of Foshan's culture, enhance the international competitiveness of Foshan's local culture, create a Foshan cultural and creative brand, stimulate the vitality of folk culture and cultural creativity, and provide the driving force for the development of a modern harmonious society.

Breaking through the limitations of the current research on traditional festival visual symbols, based on the professional knowledge of visual communication design, the author conducts indepth research on traditional Chinese New Year visual symbols. Through combing the visual elements of Foshan's Spring Festival, combined with a large number of examples, the author summarizes the innovative methods of Foshan's Spring Festival visual symbol design, so that the traditional festivals are radiated with new vitality, and the festival visual design works with Chinese characteristics and the breath of the times are created. The research results can be directly carried out in the design and development of cultural and creative products to the market, so that contemporary graphic design can be radiated with strong vitality.

\section{RESEARCH AND CONSTRUCTION OF FOSHAN'S SPRING FESTIVAL CULTURAL SYMBOL SYSTEM}

Focusing on the research and induction of Foshan's Spring Festival cultural visual symbols, by using modern design research methods to construct the Foshan's Spring Festival cultural symbol system, finally the research results can be integrated with modern visual communication design, to make the traditional cultural symbols be transformed into cultural and creative consumer products that is more easily accepted and disseminated by contemporary aesthetics and consumption.

\subsection{Research on Foshan's Spring Festival Cultural Visual Symbol System}

Symbols are the generalization and performance of values and aesthetics. The meaning of the Spring Festival is presented through a series of festival activities, and visual symbols are an important part of it. As a symbolic embodiment of Foshan's regional culture, the visual symbol system of Foshan's New Year culture that people see today is the Spring Festival custom that has been naturally precipitated by Foshan people's long-term life experience. From the gradual evolution of religious worship with rich colors to collective celebrations involving the participation of the whole people, visual symbols have turned to practical functions such as reflecting real life, praising beauty, and transmitting information, gradually integrated into various expressions such as painting, literature, handicrafts with regional characteristics, and experienced a relatively stable inheritance and evolution process over time. According to resource attributes, the visual symbols of Foshan's year culture are divided into two types: tangible culture and intangible cultural resources. Foshan, as the core area of the Pearl River Delta in the era of farming civilization, the communication media and forms of visual symbols of Spring Festival culture are mainly through ceremonies, celebrations, clothing, food, buildings, gifts and other channels. With the continuous improvement of contemporary living standards, the integration of traditional values and modern social lifestyles under the practice of socialist spiritual civilization construction and changes in customs and customs. Especially in recent years, with the promotion of digital information technology, cultural changes have also taken place in the millennium. The rise of new forms of communication has enabled Spring Festival Culture to use more channels such as film and television, the Internet, advertising, and cultural and creative products.

\subsection{Research on the Characteristics of Foshan's Spring Festival Cultural Visual Symbols}

Foshan's Spring Festival customs are a concentrated display of Lingnan's cultural traditions, condensing folk ethics, life consciousness, national emotions, and aesthetic consciousness, as well as religious feelings. 


\subsubsection{Regional Characteristics}

Foshan's Spring Festival customs followed the folklore inheritance of immigrants from the Central Plains and combined with Lingnan customs to form unique and distinctive Lingnan local characteristics. Different from the folk custom of the Spring Festival in the Central Plains, the ritual procedures of the Lingnan New Year Festival are simplified in form and scale compared with the complicated rituals of the Central Plains, and the expression forms are more abundant, so that the visual symbol system is unique.

\subsubsection{Historic Characteristics}

Foshan's Spring Festival customs have been inherited and developed for thousands of years, bringing together the simple emotions and beautiful visions of the working people under the farming culture for the world, nature, and life. As the node of social and family emotional communication, through collective participation of people, universal communication can be realized and coexistence experience can be obtained.

\subsubsection{Social Characteristics}

From the twenty-third of the twelfth lunar month to the sixteenth of the first lunar month, there are sacrificing the kitchen god, sweeping the house, swaying the spring (posting door god and spring festival couplets), opening the oil pot, shopping on the flower street, selling laziness, worshiping ancestors, staying up late or all night on New Year's Eve, New Year's greetings, acting to reward the gods, Lunar Lanterns, Lantern Festival outing, lettuce fair, walking through the Tongji Bridge on the 16th of the first lunar month, "walking to the ancestral Temple, worshiping the North King", etc. Celebrating the whole world, people and "gods" enjoy together until the fifteenth of the first lunar month, it is a collective carnival and a celebration of the whole people, forming a relatively fixed regional culture, group culture, with high humanistic value.

\subsection{Research on the Connotation of Foshan's Spring Festival Cultural Visual Symbols}

The inherent spiritual and cultural needs of Foshan people for generations are the driving force for the tradition of the Spring Festival customs to this day. The visual symbols of the Spring Festival culture associated with it not only embellish and enhance the festive atmosphere in the life scenes, and show the role of folk life, and they are also one of the unique cultural symbols of Lingnan culture, with rich connotations.

\subsubsection{Ethical Education and Respecting for Ancestors}

Foshan Spring Festival Culture pays attention to the promotion of the spirit of loyalty and filial piety in the Spring Festival culture and the inheritance of traditional Chinese ethics, and closely focuses on this theme to carry out a series of festive food, celebration etiquette and other annual activities, forming a rich representation of the visual symbols of Foshan Spring Festival culture, and revealing the theme of respect for the tradition of loyalty and filial piety and awe of heaven, earth and natural laws.

\subsubsection{Praying for Good Luck, Seeking Benefits and Avoiding Disasters}

The Spring Festival evolved from praying for the first year of the year in ancient times. Foshan's Spring Festival custom was inherited from the Central Plains culture along with the trekking and migration of Lingnan ancestors, and was born out of the primitive society's festival prayer and sacrifice traditions of the agricultural civilization of the Yellow River Basin. Foshan, as one of the "Four Famous Towns in China", has flourished in the Ming and Qing dynasties. It is also the birthplace of Cantonese merchants, one of China's "five major business gangs". It has a strong business atmosphere. Practical and mercantile is a major feature of the cultural symbol of Foshan.

\subsubsection{Being Compatible and Friendly, Peaceful and Kind}

Foshan's new year's grand special activities such as shopping on the flower street, walking through Tongji Bridge, "walking to the ancestral Temple, worshiping the North King" reflect the extensive collection of Foshan people, fully embody the compatibility characteristics of Lingnan culture, and also incorporate the Foshan people's tradition of "hoping for the luck" to form their own unique visual language. 


\section{CONCLUSION}

The research and practice methods of modern visual communication design can construct a mechanism and way of harmonious coexistence between traditional festival culture and contemporary people's life. In today's era, with increasing globalization and rapid urbanization, people's living style, communication style, cultural environment, etc. are undergoing drastic changes. This is the most important social and ecological reason for the decline in the attractiveness of traditional festivals. However, people's group life has not changed, people's state of facing difficulties and challenges has not changed, and people's desire for a spiritual home will not change. Therefore, it is necessary for people look for values and cultural elements that are compatible with traditional festival culture and contemporary social life, such as "communication and harmony" - multiple and harmonious communication between human and nature, human and ancestors and history, human and human, and human's own physiology and psychology. By digging the new connotation of traditional festival culture, with the help of modern design methods, it is of great significance to inherit and carry forward to the culture, and enhance cultural vitality and attractiveness, to make tourists from all over the world share the traditional and creative Foshan special Spring Festival cultural feast.

\section{AUTHORS' CONTRIBUTIONS}

This paper is independently completed by Dapeng Zhou.

\section{REFERENCES}

[1] Xie Zhongyuan, A Probe into the Development and Motivity ofLocal Folk Culture Since the Reform and Opening-Up Taking the Foshan Lion Dance as an Example [J]. Journal of Yangtze University: Social Sciences Edition, 2019, 42(06): 28-35. (in Chinese)

[2] Chen Enwei, The Heritagisation Practice and the Meaning Production and Sharing ofIntangible Heritage - A Case Study of "Xingtongji" Folk Custom in Foshan [J]. Journal of Chongqing University of Arts and Sciences, 2018, 37(01): 11-19. (in Chinese)

[3] Chen Enwei, The Contemporary Inheritance and Protective Strategy of Xing Tongji
Custom in Foshan [J]. Journal of Foshan University(Social Science), 2017, 35(05)-10. (in Chinese)

[4] Liang Jianqing, Foshan Spring Festival Dietetic Custom and Harmonious Society [J]. Journal of Foshan University (Social Science), 2017, 35(03): 47-51. (in Chinese)

[5] Guan Hong, Inheritance of Foshan Spring Festival Customs and Creation of Festival Atmosphere [J]. Cultural Heritage, 2012(02): 152-162. (in Chinese)

[6] Zhou Dapeng, Cool Thoughts on "Intangible Heritage" Culture Entering Campus Under the Craze of Aesthetic Education in Colleges and Universities - Taking Art Design as an Example [J]. Aesthetics, 2020(03): 42-44. (in Chinese) 